\title{
Seiridium cardinale on Juniperus species in Greece
}

\author{
By P. Tsopelas ${ }^{1}$, I. Barnes ${ }^{2}$, M. J. Wingfield ${ }^{2}$ and S. Xenopoulos ${ }^{1}$ \\ ${ }^{1}$ NAGREF-Institute of Mediterranean Forest Ecosystems, Terma Alkmanos, 11528 Athens, Greece. \\ E-mail: tsop@fria.gr; ${ }^{2}$ Forestry and Agricultural Biotechnology Institute (FABI), Department of \\ Genetics, University of Pretoria, Pretoria, South Africa
}

\begin{abstract}
Summary
Seiridium cardinale, the cause of cypress canker disease, was found on Juniperus foetidissima, J. excelsa, $J$. oxycedrus and J. phoenicea, in a number of natural juniper woodlands in Greece. The presence of infections was sporadic in most cases, with a limited number of plants affected by the pathogen. At one locality in the Prespes Lakes region of northern Greece, however, the incidence of infection was very high, especially on $J$. foetidissima and $J$. excelsa. The identity of $S$. cardinale was confirmed using morphological characters and comparisons of DNA sequences for the $\beta$-tubulin gene region. The pathogenicity of $S$. cardinale isolates from Juniperus and Cupressus was verified in cross-inoculation trials on both potted and field grown plants.
\end{abstract}

\section{Introduction}

The fungus Seiridium cardinale (Wag.) Sutton \& Gibson causes a serious canker disease on cypress trees and other members of the Cupressaceae. It was originally reported in California on Monterey cypress (Cupressus macrocarpa Hartweg.; WAGENER 1928) and it is believed that the disease was spread from North America to many other areas of the world. The fungus has been found in South America, South Africa, Europe, Asia, Australia and New Zealand (Grasso and Ponchet 1979; Graniti 1998). Two other species, Seiridium unicorne (Cke. \& Ell.) Sutton and Seiridium cupressi (Guba) Boesew. [teleomorph: Leptentypa cupressi (Natrass et al.) Swart], also cause canker diseases on species of Cupressaceae (Graniti 1998).

Juniperus spp. are evergreen shrubs or small trees in the family Cupressaceae. They are widely distributed throughout Greece growing among other forest species usually in the understorey, but they also dominate in certain areas forming shrubby juniper woodlands. They usually occur on dry rocky sites playing a significant role in the protection of soils against erosion and providing important habitats for birds and mammals.

Little attention has been given to Juniperus spp. as hosts of S. cardinale. WAGENER (1939) reported S. cardinale on J. chinensis L., J. sabina L. var. tamariscifolia Ait., J. virginiana L. and J. scropulorum Sargent. The fungus was successfully inoculated on plants of J. communis L., in Britain and Italy (Strouts 1973; Parrini and PAnconesi 1981). There are also reports of $S$. unicorne on a number of Juniperus spp. from different countries (SASAki and Kobayashi 1975; Tisserat et al. 1991).

In a preliminary report, XeNopoulos (2001) recorded the presence of $S$. cardinale on three Juniperus spp., J. foetidissima Willd., J. excelsa Bieb. and J. oxycedrus L. in a natural stand close to the Prespes Lakes in northern Greece. The present study provides a more detailed account of the presence of $S$. cardinale on Juniperus species growing in natural woodlands in various areas of Greece. The identity of the fungus was confirmed based on 
morphological characters and on DNA sequence comparisons and the pathogenicity of S. cardinale isolates from Juniperus and Cupressus was tested in cross-inoculation trials.

\section{Materials and methods}

\subsection{Collection sites, isolation and morphological examination}

The presence of $S$. cardinale on various Juniperus spp. growing under natural conditions was investigated between 2001 and 2004. Surveys were made in the areas of the Prespes Lakes region in northern Greece, and the Parnassos and Giona mountains in central Greece, parts of the Peloponnese and the Attica regions as well as the island of Lefkada in the Ionian Sea. Samples from branches with cankers and die-back symptoms were collected and transferred to the laboratory. The species of Juniperus examined in these areas are listed in Table 1.

Branches with cankers were examined under the dissecting microscope to detect acervuli of $S$. cardinale. Isolations were made by transferring spore masses from acervuli onto Petri dishes containing potato dextrose agar (PDA; Oxoid, Hampshire, UK). Where acervuli were absent, isolations were made by first removing the outer tissues near the canker margins with a sterile scalpel and then aseptically transferring small pieces of the underlying affected bark onto PDA. Cultures were incubated at $25^{\circ} \mathrm{C}$ and exposed to diffuse daylight. In some of the cultures, sterilized cypress (Cupressus sempervirens L.) seeds were added to facilitate the formation of acervuli. Growth characteristics of isolates from Juniperus spp. were compared with isolates from C. sempervirens and C. macrocarpa trees from Greece and one isolate (CMW 18794) from Italy.

Conidia from acervuli on infected juniper branches and those that developed in culture were examined in water using a bright-field microscope at 400x magnification. The lengths and widths of 50 conidia were measured for two isolates, CMW 18794 from C. sempervirens and CMW 18606 from J. excelsa.

\subsection{DNA extraction, sequencing and phylogenetic analyses}

Isolates used for DNA extraction were grown on $2 \%$ malt extract agar (MEA; Biolab, Midrand, Johannesburg) for 2 weeks. Aerial mycelium was scraped from the surface of the cultures, placed in sterilized $1.5 \mathrm{ml}$ Eppendorf tubes and lyophilized. Lyophilized mycelium was then crushed into a fine powder using liquid nitrogen. DNA extraction was carried out using the phenol/chloroform method described by BARNEs et al. (2001).

Two areas of the $\beta$-tubulin gene were amplified using primer combinations $\mathrm{Bt} 1 \mathrm{a} / \mathrm{Bt} 1 \mathrm{~b}$ and Bt2a/Bt2b (Glass and Donaldson 1995). PCR and sequencing conditions and

Table 1. Occurrence of Seiridium cardinale on Juniperus spp. in different areas of Greece

\begin{tabular}{|lllcl|}
\hline Locality & Juniperus sp. & $\begin{array}{l}\text { Latitude (N)/ } \\
\text { longitude (E) }\end{array}$ & $\begin{array}{c}\text { Altitude } \\
\text { (m a.s.l.) }\end{array}$ & Abundance \\
\hline Prespes & J. excelsa & $40^{\circ} 49^{\prime} / 21^{\circ} 01^{\prime}$ & 900 & Common \\
& J. foetidissima & $40^{\circ} 49^{\prime} / 21^{\circ} 01^{\prime}$ & 900 & Common \\
Giona Mt & J. oxycedrus & $40^{\circ} 49^{\prime} / 21^{\circ} 01^{\prime}$ & 900 & Sporadic \\
Parnassos Mt & J. foetidissima & $38^{\circ} 28^{\prime} / 22^{\circ} 26^{\prime}$ & 1100 & Sporadic \\
& J. foetidissima & $38^{\circ} 32^{\prime} / 22^{\circ} 12^{\prime}$ & 1200 & Sporadic \\
Parnis Mt & J. oxycedrus & $38^{\circ} 36^{\prime} / 22^{\circ} 22^{\prime}$ & 500 & Sporadic \\
Korinthia & J. oxycedrus & $38^{\circ} 08^{\prime} / 23^{\circ} 41^{\prime}$ & 800 & Sporadic \\
Lefkada & J. oxycedrus & $37^{\circ} 58^{\prime} / 22^{\circ} 38^{\prime}$ & 750 & Sporadic \\
& J. phoenicea & $38^{\circ} 40^{\prime} / 20^{\circ} 33^{\prime}$ & 30 & Sporadic \\
\hline
\end{tabular}


reactions were the same as those described in BARNEs et al. (2001) with two exceptions. Amplicons were purified using Sephadex G-50 columns (Sigma-Aldrich, Steinnheim, Germany) and sequence reactions were run on an ABI PRISM ${ }^{\mathrm{TM}} 3100$ Autosequencer (Applied Biosystems, Foster City, CA, USA). Sequences obtained in this study (see GenBank numbers in Table 2) were aligned with, and compared to, other sequences obtained from GenBank, available through NCBI at http://www.ncbi.nlm.nih.gov/ Genbank/index.html (КАTOH et al. 2005). Alignments were carried out online using MAFFT Version 5.8 (http://align.bmr.kyushu-u.ac.jp/mafft/online/server) with the L-INS-I strategy and the gap opening penalty set at 1.53. A partition homogeneity test (PHT) with 100 replicates was performed in PAUP* Version 4.0b10 (Phylogenetic Analysis Using Parsimony; Swofford 2002) to determine the combinability of the sequence data sets. Parsimony analyses were carried out using the Heuristic search option with tree bisectionreconnection and 100 random stepwise additions in PAUP. All characters were given equal weight and gaps were treated as a fifth character. Confidence levels of the branching points were determined using a bootstrap consensus of 1000 replicates. Seiridium papillatum Z.Q. Yuan was used as the outgroup and was treated as a monophyletic sister group to the ingroup.

\subsection{Inoculation trials}

In two inoculation trials, four Juniperus species were used in total. In the first trial, 2- to 4-year-old seedlings of J. oxycedrus (Attika seed source), J. macrocarpa Sm. (Attika seed source) and J. phoenicea L. (Milos island seed source) were used in 12-l plastic pots containing a mixture of farm soil and sphagnum peat $(2: 1 \mathrm{v} / \mathrm{v})$. In this trial, 2 -year-old cypress (C. sempervirens) saplings were also used in pots. The plants were placed outdoors in the Amygdaleza nursery (15 km from Athens) and irrigated twice a week during the dry seasons. In the second trial, mature trees of $J$. oxycedrus and J. foetidissima present in a natural woodland on Mount Giona, at elevation $1250 \mathrm{~m}$, where natural infections by the fungus were found previously, were inoculated.

Inoculations in both trials were performed in October of 2002 and the experiment was terminated after 7 months, in May 2003. In potted plants, inoculations were made on the lower stem of the plants. Stem diameters at the inoculation points ranged from 6 to $11 \mathrm{~mm}$. After inoculation, pots were arranged in a completely randomized design. Each mature tree received two inoculations on separate branches of $11-16 \mathrm{~mm}$ in diameter. Details of plant number, age and stem diameter at inoculation points are listed in Table 3.

Two isolates of $S$. cardinale were used in the inoculation experiments. These were an Italian isolate from C. sempervirens (CMW 18794) and an isolate from J. foetidissima (CMW 18605). In the trial with potted plants, both isolates were used, whereas in the field trial on mature trees, only isolate CMW 18605 was used. Inoculum was prepared from stems of Sorghum vulgare Pers. Stems approximately $1 \mathrm{~mm}$ in diameter were cut into pieces $15 \mathrm{~mm}$ in length and autoclaved for $30 \mathrm{~min}$ at $121^{\circ} \mathrm{C}$. Fungal isolates were grown in Petri dishes containing PDA for 1 week at $25^{\circ} \mathrm{C}$ after which the autoclaved $S$. vulgare stems were added and then further incubated for 3 weeks. For inoculations, a hole, $1.5 \mathrm{~mm}$ in diameter, was made on the bark of the stems and branches and the fungus-covered stems inserted (Ponchet and Andréoli 1984). Sterile $S$. vulgare stems were used in five plants of each species in the trial with potted plants, and also on a separate branch of all the inoculated mature trees to serve as controls.

Inoculated plants in the nursery were examined monthly and the development of cankers and other symptoms noted. Mature plants in the natural woodland were examined once before harvesting, 5 months after inoculation. At sampling, stems of all harvested plants were examined under the dissecting microscope and the presence of acervuli in the infected area of the bark recorded. Lesion (canker) lengths were measured for all inoculated stems 


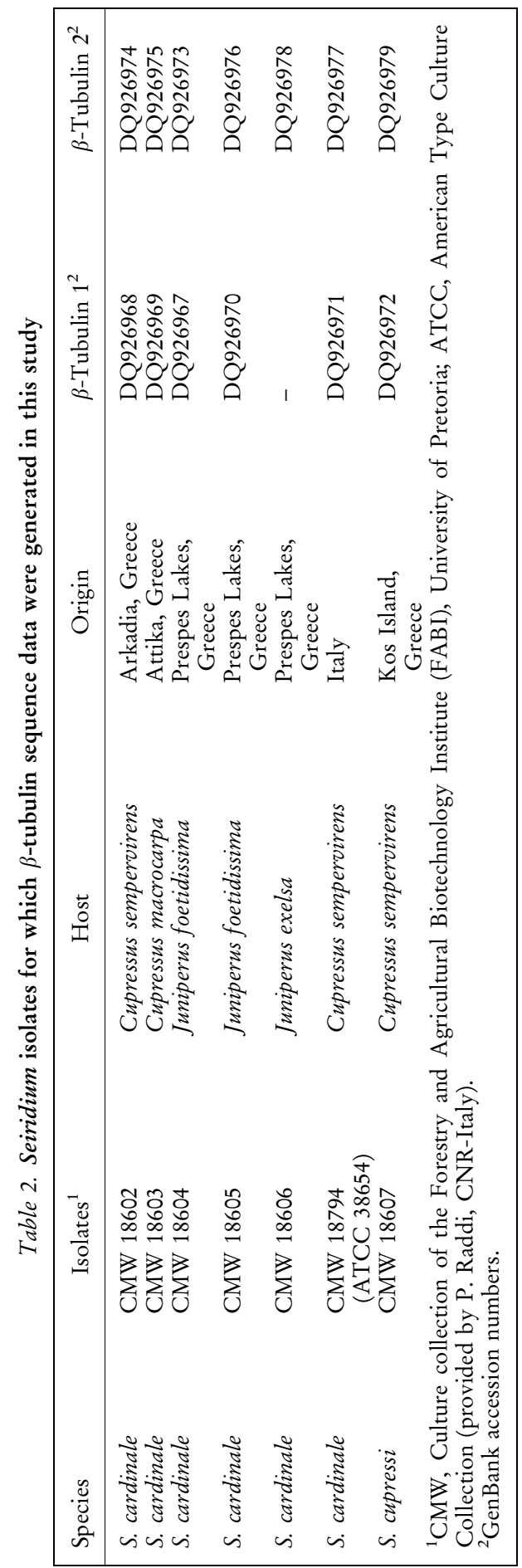


Table 3. Mean lesion (canker) length of Seiridium cardinale on Juniperus and Cupressus species, 7 months after inoculation $(\mathrm{mm})$

\begin{tabular}{|c|c|c|c|c|c|c|}
\hline $\begin{array}{l}\text { Inoculated } \\
\text { plants }\end{array}$ & $\begin{array}{l}\text { Fungal } \\
\text { isolate }^{1}\end{array}$ & $\begin{array}{l}\text { Number of } \\
\text { inoculations }\end{array}$ & $\begin{array}{l}\text { Number of } \\
\text { infections }\end{array}$ & $\begin{array}{l}\text { Age of } \\
\text { plants } \\
\text { (years) }\end{array}$ & $\begin{array}{l}\text { Diameter at } \\
\text { inoculation } \\
\text { point }(\mathrm{mm})\end{array}$ & $\begin{array}{c}\text { Lesion } \\
(\text { canker })^{3} \\
\text { length }^{3}(\mathrm{~mm})\end{array}$ \\
\hline \multicolumn{7}{|l|}{ Potted plants } \\
\hline J. oxycedrus & 1 & 10 & $9(10)$ & 4 & $8-11$ & $46.1 \mathrm{a} \pm 2.3$ \\
\hline J. oxycedrus & 2 & 9 & 8 & 4 & $8-10$ & $44.9 a \pm 1.9$ \\
\hline J. macrocarpa & 1 & 11 & $9(10)$ & 4 & $7-10$ & $48.6 a \pm 4.6$ \\
\hline J. macrocarpa & 2 & 9 & 8 & 4 & $8-10$ & $47.63 a \pm 1.9$ \\
\hline J. phoenicea & 1 & 11 & $9(11)$ & 2 & $5-7$ & $52.33 a \pm 3.9$ \\
\hline C. sempervirens & 1 & 10 & 10 & 2 & $7-15$ & $84.4 b \pm 5.0$ \\
\hline C. sempervirens & 2 & 10 & $9(10)$ & 2 & $8-12$ & $85.2 \mathrm{~b} \pm 4.2$ \\
\hline \multicolumn{7}{|l|}{ Field grown } \\
\hline J. oxycedrus & 2 & 16 & 16 & $>20$ & $11-15$ & $81.1 \mathrm{c} \pm 9.9$ \\
\hline J. foetidissima & 2 & 16 & 16 & $>20$ & $12-15$ & $45.1 \mathrm{a} \pm 3.0$ \\
\hline \multicolumn{7}{|c|}{$\begin{array}{l}{ }^{1} 1=\text { isolate CMW } 18794 ; 2=\text { isolate CMW } 18605 \text {. } \\
{ }^{2} \text { Numbers in brackets show total number of infected plants, including those with dead tops, which } \\
\text { were not considered in the statistical analysis. } \\
{ }^{3} \text { Values are mean } \pm \text { SE. Numbers followed by the same letter do not differ significantly according } \\
\text { to Duncan's multiple range test }(\mathrm{p}=0.05) \text {. }\end{array}$} \\
\hline
\end{tabular}

and branches by lightly scraping the bark from the periphery of the canker and noting the discolouration of the inner bark tissues and sapwood. Re-isolation of the fungus was attempted from the canker margins on a representative sample of plants from each treatment to confirm the presence of $S$. cardinale, especially from cankers that did not develop acervuli of the fungus.

Analysis of variance was performed on lesion lengths in every treatment and Duncan's multiple range test $(\mathrm{p}=0.05)$ was used to compare the mean values, using spss software (SPSS Inc., Chicago, IL, USA).

\section{Results}

\subsection{Disease occurrence, symptoms and morphological characteristics}

Infections by $S$. cardinale were found on four different Juniperus species in natural woodlands, in a number of different localities of Greece (Table 1). In most areas, the presence of infections was sporadic, with a limited number of plants affected at each locality. However, in an area close to Psarades village in the Prespes Lakes region of northern Greece, the intensity of infection was very high, especially on J. foetidissima and J. excelsa. Juniperus oxycedrus was also found to be infected by the fungus in this area, but disease severity was lower on this species. In Parnassos and Giona Mts of central Greece, $S$. cardinale infections were detected on a limited number of J. foetidissima plants at high altitudes. At a different locality of Parnassos Mt, at lower altitudes, the fungus was also detected on J. oxycedrus plants. Infections on J. oxycedrus were also found in Parnis Mt and Korinthia Prefecture (Kaliani village), in southern Greece. On the west coast of Lefkada Island (Porto Katsiki), S. cardinale was detected on J. phoenicea.

Most infected junipers were found in close proximity to infected cypress trees, the main hosts of $S$. cardinale in Greece. However, in Prespes Lakes region in northern Greece and at high altitudes of Parnassos and Giona mountains, $S$. cardinale infections were found only on junipers. 
Affected junipers showed symptoms of die-back on one or more top or lateral branches. In some cases a major part of the plant crown was dead. On closer examination, elongated cankers were evident on branches and/or the main stem. These were similar to the cankers formed on cypress trees, with abundant resin exudation. They became more evident by removing the outer bark to expose the dark brown, dead tissue, which was usually impregnated with resin, while the surrounding healthy tissue was pearl white. Acervuli of the pathogen appeared scattered over the cankered areas of the bark as small black dots that were barely visible to the naked eye.

Seiridium cardinale was consistently isolated from bark tissue as well as from spore masses in acervuli. Isolates from Juniperus spp. were very similar in cultural morphology to those from C. sempervirens and C. macrocarpa trees in Greece and the isolate from Italy. Colonies on PDA showed a dense floccose aerial mycelium, whitish to grey, turning to greyish olive-green in older cultures. The colour on the reverse side of cultures varied from pinkish-salmon to light orange. Radial growth at $25^{\circ} \mathrm{C}$ was $10-12 \mathrm{~mm} /$ week.

Black conidial masses were formed on the cypress seeds, 2-3 weeks after their placement on cultures. Conidial masses were rare on cultures lacking cypress seeds. Conidia from Juniperus isolates were indistinguishable from those of the isolates from Cupressus spp. The characteristic 5-septate, oblong-fusiform conidia of $S$. cardinale $(20-28 \times 8-9 \mu \mathrm{m})$ were observed, with characteristic hyaline, short (approximately $1 \mu \mathrm{m}$ ) and conical apical cells.

\subsection{DNA extraction, sequencing and phylogenetic analyses}

Sequencing the $\beta$-tubulin 1 and 2 PCR products using the forward and reverse primers produced sequences of approximately 450 and $510 \mathrm{bp}$ long, respectively. Translation of the consensus sequences into amino acids revealed one intron present in the $\beta$-tubulin 1 region (56 bp long) flanked by exons of sizes 141 and 267-276 bp depending on the quality of the ends of the sequences. The sequences of the $\beta$-tubulin 2 region contained an intron of between 78 and $112 \mathrm{bp}$ followed by an exon of $42 \mathrm{bp}$, an intron of $67 \mathrm{bp}$ for the $S$. cardinale isolates and $66 \mathrm{bp}$ for the $S$. cupressi isolates and an exon of $182 \mathrm{bp}$. After alignment in MAFFT with additional Seiridium sequences, the individual data sets consisted of 406 and 478 characters for $\beta$-tubulin 1 and 2 regions, respectively.

The PHT with the heuristic search option in PAUP showed significant congruence with a p-value of 0.65 . Individual data sets were, therefore, combined in the phylogenetic analyses. Of 877 total characters: 729 characters were constant, 82 variable characters were parsimony-uninformative and 66 characters were parsimony-informative. Fourteen most parsimonious trees were generated with a tree length of 170 , a consistency and retention index value of 0.93 and 0.95 , respectively, and a $\mathrm{g} 1$ value of -0.71 . The slight variation observed in the topology of the trees occurred in the placement of some of the $S$. cardinale isolates. The rest of the tree topology remained identical in all 14 trees. One most parsimonious tree is illustrated in Fig. 1.

All isolates obtained from Juniperus and Cupressus species in this study grouped with the previously identified $S$. cardinale clade, including the authenticated isolate from ATCC 38654 (CMW 18794) from C. sempervirens in Italy. The one isolate (CMW 18607) collected from C. sempervirens and identified as S. cupressi based on morphology, fell within the $S$. cupressi clade. It had identical sequence to isolate (CMW 1646) collected from the same region.

\subsection{Inoculation trials}

All Juniperus and Cupressus species used in the inoculation trials became infected by both isolates of $S$. cardinale. In the field trial, all plants developed cankers on the inoculated branches. In potted plants, 67 of 70 inoculated plants developed infection symptoms 


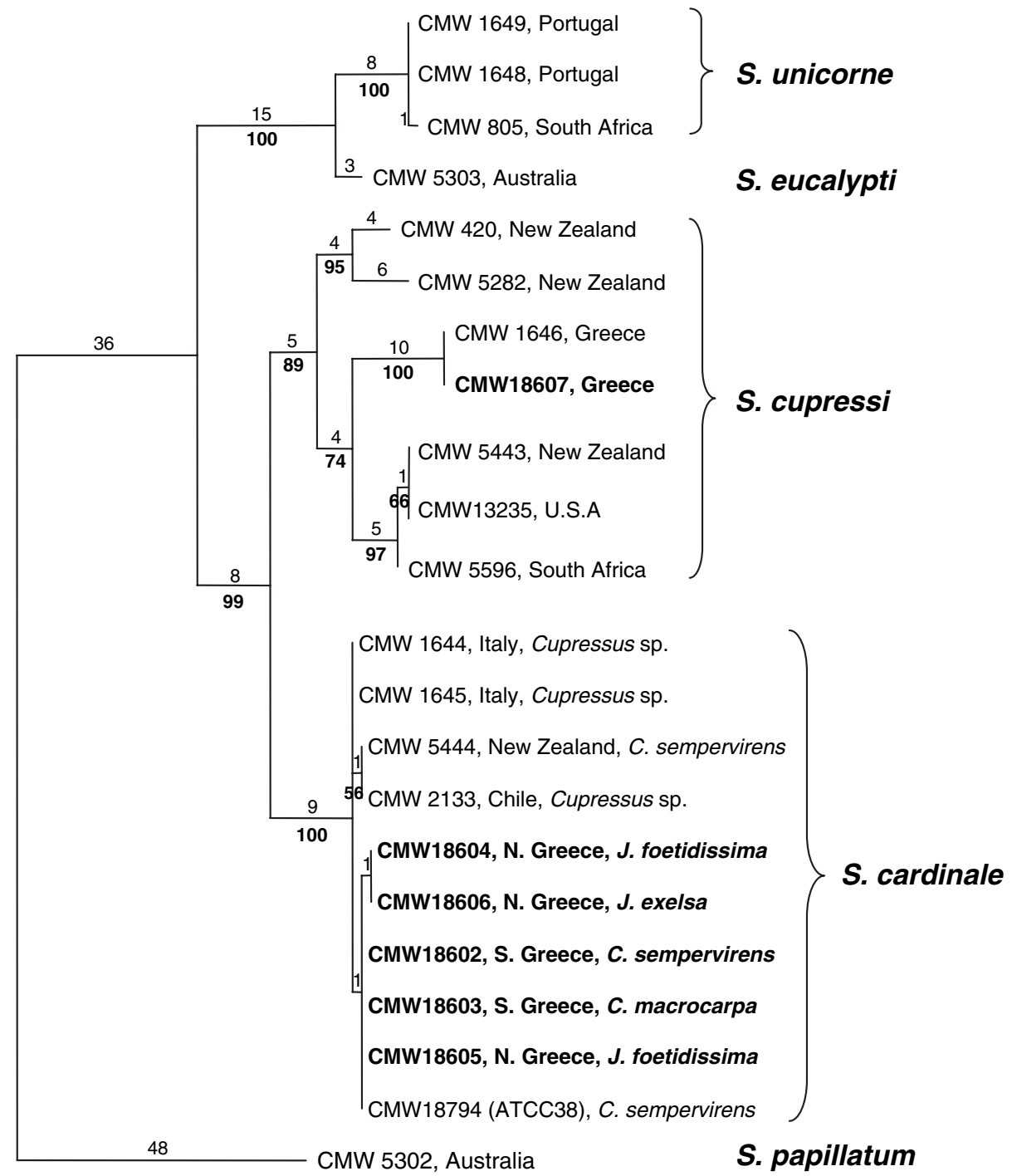

Fig. 1. Phylogenetic tree of Seiridium species based on $\beta$-tubulin sequence data. The most parsimonious tree was obtained using the heuristic search option in PAUP. The isolates from Juniperus and Cupressus fall within the $S$. cardinale clade based on sequence data thus supporting the morphological identification of these isolates as $S$. cardinale. An additional isolate collected from C. sempervirens falls within the $S$. cupressi clade showing that both pathogens, $S$. cardinale and S. cupressi, are present within Greece. Branch lengths are indicated above the branches while bootstrap confidence levels are represented below the branches

(95.7\%). Of the remaining plants, one died of unknown cause and two saplings failed to become infected. Most plants survived during the 7-month incubation period. In five potted plants, mainly those with small diameters ( $\leq 6$ to $7 \mathrm{~mm}$ ), the terminal shoots died 3-4 months after inoculation because of stem girdling and had to be excluded from lesion 
measurements made at the end of the experiment. Acervuli were present in almost all the infected trees in the nursery at harvest in May. These structures were rare, however, on the infected branches of Juniperus trees inoculated in the natural woodland.

In the nursery trial, no significant differences $(\mathrm{p}=0.05)$ were found in lesion length for two isolates of $S$. cardinale, from Juniperus (CMW 18605) and Cupressus (CMW 18794) on any of the Juniperus spp. inoculated (Table 3). Similarly, there were no significant differences in virulence between these two isolates on the Cupressus saplings inoculated. Significant differences in lesion length were, however, found between potted J. oxycedrus plants and those of the same species growing in natural conditions. Lesion lengths on branches of the field trees ranged between 32 and $160 \mathrm{~mm}$ (average $81 \mathrm{~mm}$ ), compared with $29-55 \mathrm{~mm}$ (mean $45 \mathrm{~mm}$ ) on potted plants of the same species. Significant differences in lesion length were also observed between J. oxycedrus and J. foetidissima field grown plants, averaging $81 \mathrm{~mm}$ and $45 \mathrm{~mm}$, respectively. In potted plants, lesion length was greater on Cupressus plants (ranging between 62 and $111 \mathrm{~mm}$, mean $85 \mathrm{~mm}$ ) than all Juniperus species that averaged $45-52 \mathrm{~mm}$.

\section{Discussion}

This study represents the first detailed assessment of the presence of $S$. cardinale in natural juniper woodlands in various areas of Greece. The pathogen was previously recorded on Juniperus foetidissima, J. excelsa and J. oxycedrus in a brief communication (Xenopoulos 2001), but this is the first record of its occurrence on J. phoenicea. This study also represents the first pathogenicity tests with the fungus on Juniperus spp. in Greece. There are also no reports of $S$. cardinale or any other Seiridium sp. on these Juniperus spp. elsewhere in the world.

Of the three Seiridium spp. known to be associated with cypress cankers, S. unicorne and $S$. cupressi are morphologically very similar to each other. They are thus often confused with each other or misidentified (SwART 1973; CHOu 1989). DNA-based methods have, however, provided a means to conclusively identify these species (BARNEs et al. 2001). Isolates CMW 420 and CMW 5443 used in this study were previously identified as representing $S$. unicorne, based on morphology but were clearly shown to represent S. cupressi by BARnes et al. (2001). The isolate CMW 18607 collected from C. sempervirens in Greece was originally identified based on morphology as $S$. cupressi and this was confirmed here using DNA sequence comparisons. On the other hand, $S$. cardinale can be identified based on conidial morphology, with short and conical, hyaline apical cells or appendages (BoESEWINKEL 1983). It was, therefore, not surprising that the isolates collected from Juniperus and Cupressus in this study resided in the $S$. cardinale clade in the phylogram based on $\beta$-tubulin sequences.

The pathogenicity of $S$. cardinale from Juniperus and Cupressus was verified in inoculation tests on three of the species found to be naturally infected in this study. Inoculation tests with $J$. excelsa were not performed, because seedlings of this species were not available. Another juniper, J. macrocarpa, which was not found infected under natural conditions and has not been reported before as a host of $S$. cardinale, was also successfully inoculated in the trials and can be considered susceptible to the pathogen.

Statistical analysis of the lesion lengths showed that the two isolates of $S$. cardinale (from juniper and cypress) did not differ significantly in virulence when inoculated on the same plant species under the same conditions. There were also no significant differences in virulence of different $S$. cardinale isolates used in inoculation tests on clones of C. sempervirens in Italy (RADDI and PANCONESI 1984).

Inoculated plants showed some differences in relative susceptibilities to $S$. cardinale. However, the number of trees tested was small and general conclusions cannot be drawn on the basis of these results. Lesion length was significantly greater on C. sempervirens 
seedlings than on any of the Juniperus spp. grown under the same conditions, while differences in lesion length among the different Juniperus spp. were not significant. Lesion lengths on branches of mature J. oxycedrus trees were significantly greater than those on $J$. foetidissima inoculated with the same isolate of $S$. cardinale. However, under natural conditions in the Prespes Lakes, the pathogen was more virulent on J. foetidissima than on J. oxycedrus.

Significant differences were observed in lesion length between J. oxycedrus trees growing in the nursery at low elevation and the mature plants growing under natural conditions at high elevation where relative humidity is high and fungal growth was greater. These results are consistent with those of previous studies on cloned C. sempervirens (SANTINI et al. 1997; S. Xenopoulos, unpublished data), where susceptibility of trees to $S$. cardinale was significantly greater in moist areas than in where conditions were drier.

Seiridium cardinale has been known in Greece since the early 1960s and has caused significant damage to $C$. sempervirens in plantations in many areas of the country (Xenopoulos and Diamandis 1985; Tsopelas and Xenopoulos 2006). In some areas, the infection level has been $>90 \%$. However, in natural stands of this species on some of the Aegean islands, infection levels have been very low (Xenopoulos and Diamandis 1985; P. Tsopelas, unpublished data). This is similar to the situation in California, where C. macrocarpa in natural stands has not been affected while those grown in gardens and plantations have been severely infected by $S$. cardinale (WAGENER 1939). Results of the present study reflect a similar pattern with Juniperus spp., which are only mildly affected in natural woodlands. In only one locality of the Prespes Lakes region, the disease has caused considerable damage to junipers, causing extensive die-back on branches and in many cases killing whole trees. The environmental conditions in this area favour the spread of the pathogen as the region receives heavy rain and the relative humidity of the atmosphere is very high for long periods of time.

\section{Acknowledgements}

The DST/NRF and the Centre of Excellence in Tree Health Biotechnology (CTHB), South Africa, is acknowledged for financial assistance. We are also grateful to Dr P. Raddi, CNR Italy, for providing isolate ATCC 38654 of Seiridium cardinale.

\section{References}

Barnes, I.; Roux, J.; Coetzee, M. P. A.; Wingfield, M. J., 2001: Characterization of Seiridium spp. associated with cypress canker based on $\beta$-tubulin and histone sequences. Plant Dis. 85, 317-321.

Boesewinkel, H. J., 1983: New records of the three fungi causing cypress canker in New Zealand, Seiridium cupressi (Guba) comb. nov. and S. cardinale on Cupressocyparis and S. unicorne on Cryptomeria and Cupressus. Trans. Br. Mycol. Soc. 80, 544-547.

Сноu, С. К. S., 1989: Morphological and cultural variation of Seiridium spp. from cankered Cupressaceae hosts in New Zealand. Eur. J. For. Path. 19, 435-445.

Glass, N. L.; Donaldson, G. C., 1995: Development of primer sets designed for use with the PCR to amplify conserved genes from filamentous Ascomycetes. Appl. Environ. Microbiol. 61, 13231330.

Graniti, A., 1998: Cypress canker: a pandemic in progress. Annu. Rev. Phytopathol. 36, 91-114.

Grasso, V.; PoncheT, J., 1979: Historique, distribution gèographique et hôtes du Coryneum cardinale Wag. In: Seminario: Il Cipresso Malattie e difesa. Ed. by Grasso, V.; Raddi, P., Firenze: Agrimed, Comun. Econ. Eur, pp. 119-126.

Катон, K.; Kuma, K.; Тон, Н.; Miyata, T., 2005: Mafft version 5: improvement in accuracy of multiple sequence alignment. Nucleic Acids Res. 33, 511-518.

Parrini, C.; PANCONESI, A., 1981: Attacchi di Seiridium (Coryneum) cardinale Wag. Sutton \& Gibson su alcune Cupressaceae in vivaio. Inorm. Fitopatol. 9, 7-15.

Ponchet, J.; AndrÉoli, C., 1984: Relations hôte-parasite dans le couple Cupressus-Coryneum cardinale Wag. Agronomie 4, 245-255. 
Raddi, P.; Panconesi, A., 1984: Pathogenicity of some isolates of Seiridium (Coryneum) cardinale, agent of cypress canker disease. Eur. J. For. Path. 14, 348-354.

Santini, A.; Cassini, N.; DI Lonardo, V.; Raddi, P., I997: Canker resistance stability of some Cupressus sempervirens clones to Seiridium cardinale. J. Genet. Breed. 51, 269-277.

SASAKI, K.; KobaYashi, T., 1975: Resinous canker disease of Cupressaceae caused by Monochaetia unicornis (Cke. \& ell.) Sac1. The causal fungus and pathogenicity. Bull. Gov. For. Exp. Sta. Tokyo $271,27-38$.

STROUTs, R. G., 1973: Canker of cypresses caused by Coryneum cardinale Wag in Britain. Eur. J. For. Path. 3, 13-24.

Swart, H. J., 1973: The fungus causing cypress canker. Trans. Br. Mycol. Soc. 61, 71-82.

Swofford, D. L., 2002: Paup*. Phylogenetic Analysis Using Parsimony (*and Other Methods). Version 4. Sunderland, Massachusetts: Sinauer Associates.

Tisserat, N. A.; Nus, A.; Barnes, L. W., 1991: A canker disease of the Cupressaceae in Kansas and Texas caused by Seiridium unicorne. Plant Dis. 75, 138-140.

Tsopelas, P.; Xenopoulos, S., 2006: Cypress canker and its control in Greece. Summaries of presentations at the eleventh Hellenic Phytopathological Congress; Preveza, Greece, 1-4 October 2002. Phytopathol. Mediterr. 45, 65.

Wagener, W. W., 1928: Coryneum canker in cypress. Science 67, 584.

Wagener, W. W., 1939: The canker of Cupressus induced by Coryneum cardinale. J. Agric. Res. 58, $1-46$.

Xenopoulos, S., 2001: Three species of the genus Juniperus as new hosts of the pathogen Seiridium cardinale, the causal agent of cypress canker. Summaries of the 9th Hellenic Phytopathological Congress, Athens, Greece, 20-22 October 1998. Phytopathol. Mediterr. 40, 74 (abstract).

Xenopoulos, S.; Diamandis, S., 1985: A distribution map for Seiridium cardinale causing the cypress canker disease in Greece. Eur. J. For. Path. 15, 223-226. 